\title{
Hybrid technique for postoperative ventral hernias - own experience
}

\author{
Monika Romanowska, Tomasz Okniński, Jacek Pawlak \\ Department of General Surgery, John Paul II Specialist Western Hospital, Grodzisk Mazowiecki, Poland
}

Videosurgery Miniinv 2015; 10 (4): 534-540

DOI: $10.5114 /$ wiitm.2015.55689

\begin{abstract}
Introduction: There are many techniques which may be involved in abdominal hernia repair, from classical to tension-free. Treatment of complicated hernias has undergone evolution. Many surgeons consider the laparoscopic method as a method of choice for incisional hernia repair. Sometimes miniinvasive repair of complicated hernia is not so easy to perform. We are convinced that selected patients may benefit from combined open and laparoscopic techniques.

Aim: To present the operating technique and early results of treatment of 15 patients operated on using the 3 hybrid technique.

Material and methods: Fifteen patients suffering from recurrent incisional hernias underwent the hybrid technique for their repair between June 2012 and April 2015. The hybrid technique was performed using synthetic meshes in 14 cases and a biological implant in 1 case.

Results: The early postoperative period was uncomplicated in all cases. Within a maximum follow-up period of 32 months, two deep wound infections were observed.

Conclusions: The hybrid technique may be used in patients with recurrent incisional hernias.
\end{abstract}

Key words: synthetic materials, recurrent hernia, hybrid technique.

\section{Introduction}

Postoperative hernia is the most common complication of abdominal surgery worldwide. Incisional hernias complicate $2 \%$ to $20 \%$ of laparotomies and depend on the type of surgical technique, the method used to close the abdomen and many factors connected with the patient (age, elevated body mass index, comorbidities, previous surgery) [1, 2]. A high rate of recurrence in $20 \%$ to $50 \%$ of patients after the primary repair of the defect is another problem $[3,4]$. Many complications after an open operation, as well as technological progress, associated with innovations in synthetic materials covered by anti-adhesive substance of the ventral side, have led to the development of laparoscopic surgery $[5,6]$. This method offers many advantages: minimal pain, shorter stay in hospital, quicker return to activities, and ability to identify additional defects in the abdominal wall $[7,8]$. But in some difficult cases, defects are very large, and even after laparoscopic repair, patients are unhappy because of the cosmetic appearance of their wound. Moreover, sometimes miniinvasive repair of a complicated postoperative hernia is not easy to perform due to massive adhesions after the primary operation, which is especially dangerous during placement of laparoscopic tools into the abdominal cavity. For these reasons, we are convinced that it is worth combining the two techniques, open and laparoscopic, to maximize the benefits of both methods.

\section{Address for correspondence}

Monika Romanowska, Department of General Surgery, John Paul II Specialist Western Hospital, 11 Daleka St, 05-825 Grodzisk Mazowiecki,

Poland, phone: +48 605762 793, e-mail: monika.meszka@gmail.com 
Infections associated with incisional hernias are another problem. The use of new materials, such as biological implants, is thought to be the most suitable treatment. Collagen matrix can support tissue regeneration through neovascularization and fibroblastic cell re-population, leading to endogenous collagen formation. The use of biological materials has increased in recent years, despite their high cost and lack of convicting evidence [9-11].

\section{Aim}

The aim of the study is to present the combined operating technique and the early results of the treatment of 15 patients using this method in the Department of General Surgery in the John Paul II Specialist Western Hospital in Grodzisk Mazowiecki.

\section{Material and methods}

Fifteen patients suffering from complicated incisional hernias underwent a hybrid technique for their repair between 2012 and 2015 (from 1 June 2012 until 31 March 2015) in the Department of General Surgery of the Specialist Western Hospital in Grodzisk Mazowiecki. The group consisted of 9 men and 6 women, at the average age of 65 . Characteristics of patients are presented in Table I. Types of performed operations and postoperative complications are presented in Table II. In 1 case, there was recurrent incisional hernia after cystectomy which was primarily repaired using a Permacol mesh. This postoperative course was complicated by an enterocutaneous fistula (Photo 1). Two patients had recurrent incisional hernias after the operation of sigmoid cancer, also complicated by the appearance of an enterocutaneous fistula, and 1 woman had a large recurrent hernia after the operation of perforated sigmoid diverticulum (Hartmann's procedure) and an anastomosis of the remaining part of the colon afterwards. All cases of enterocutaneous fistulas were revealed at a different time after the operations (Table II). We used drainage and total parenteral nutrition as treatment of all fistulas. This approach was effective, and the fistulas closed after several weeks of such treatment. Another 6 patients suffered from hernias after cholecystectomy complicated by wound infection or had several open

Table I. Characteristics of patients

\begin{tabular}{|c|c|c|c|c|}
\hline No. & Gender & Age [years] & $\mathrm{BMI}\left[\mathrm{kg} / \mathrm{m}^{2}\right]$ & Comorbidities \\
\hline 1 & Male & 80 & 28.5 & $\begin{array}{l}\text { Diabetes, hypertension, renal failure, arterial fibrillation chemotherapy } \\
\text { in the past (sigmoid cancer) }\end{array}$ \\
\hline 2 & Male & 61 & 25.4 & Hypertension \\
\hline 3 & Male & 76 & 26.7 & Diabetes, hypertension, ischaemic heart disease rheumatoid arthritis \\
\hline 4 & Female & 52 & 26.2 & Hypertension \\
\hline 5 & Female & 63 & 27.3 & Hypertension \\
\hline 6 & Female & 81 & 29 & $\begin{array}{c}\text { Diabetes, hypertension, chronic obstructive pulmonary disease, ischaemic } \\
\text { heart disease, atrial fibrillation }\end{array}$ \\
\hline 7 & Male & 68 & 31.2 & Diabetes, renal failure, hypertension, after two cerebrovascular accidents \\
\hline 8 & Female & 49 & 23 & \\
\hline 9 & Male & 75 & 24.7 & Ischaemic heart disease, radiation therapy in the past (laryngeal cancer) \\
\hline 10 & Male & 78 & 25.3 & $\begin{array}{c}\text { Hypertension, ischaemic heart disease, diabetes, rheumatoid arthritis, } \\
\text { renal failure }\end{array}$ \\
\hline 11 & Female & 63 & 23.5 & Hypertension \\
\hline 12 & Male & 39 & 24.1 & \\
\hline 13 & Male & 73 & 26.1 & $\begin{array}{c}\text { Diabetes, atrial fibrillation, chronic obstructive pulmonary disease, } \\
\text { hypertension }\end{array}$ \\
\hline 14 & Male & 65 & 22 & Ischaemic heart disease, diabetes \\
\hline 15 & Female & 62 & 28 & Ischaemic heart disease, renal failure, hypertension \\
\hline
\end{tabular}


Table II. Types of performed operations and postoperative complications

\begin{tabular}{|c|c|c|}
\hline No. & Previous operations & Postoperative complications \\
\hline \multirow[t]{4}{*}{1} & Hartmann's procedure - sigmoid cancer & \\
\hline & Transverse-rectal anastomosis & Enterocutaneous fistula (6 days after second operation) \\
\hline & Skin graft & Incisional hernia \\
\hline & Open hernia repair with synthetic mesh & Recurrence \\
\hline \multirow[t]{2}{*}{2} & Cystectomy & Incisional hernia \\
\hline & Open hernia repair with biologic implant (Permacol) & Enterocutaneous fistula (10 days after second operation) \\
\hline \multirow[t]{2}{*}{3} & Sigmoid resection - sigmoid cancer & Enterocutaneous fistula (7 days after resection) \\
\hline & Open hernia repair & Recurrence \\
\hline \multirow[t]{3}{*}{4} & $\begin{array}{l}\text { Hartmann's procedure - perforated sigmoid } \\
\text { diverticulum }\end{array}$ & \\
\hline & Transverse - rectal anastomosis & Incisional hernia \\
\hline & Open hernia repair & Recurrence \\
\hline \multirow[t]{3}{*}{5} & Cholecystectomy & Incisional hernia \\
\hline & Open hernia repair & Recurrence \\
\hline & Open hernia repair with synthetic mesh & Recurrence \\
\hline \multirow[t]{3}{*}{6} & Cholecystectomy (appendectomy in the past) & Bleeding \\
\hline & Relaparotomy & Wound infection, incisional hernia \\
\hline & Open hernia repair & Recurrence \\
\hline \multirow[t]{3}{*}{7} & Cholecystectomy & Incisional hernia \\
\hline & Open hernia repair & Recurrence \\
\hline & IPOM & Recurrence \\
\hline \multirow[t]{3}{*}{8} & $\begin{array}{l}\text { Laparoscopic cholecystectomy with conversion } \\
\text { (hysterectomy in the past) }\end{array}$ & Bile leakage \\
\hline & Relaparotomy & Wound infection, incisional hernia \\
\hline & Open hernia repair & Recurrence \\
\hline \multirow[t]{2}{*}{9} & Laparoscopic cholecystectomy with conversion & Wound infection, incisional hernia \\
\hline & Open hernia repair & Recurrence \\
\hline \multirow[t]{5}{*}{10} & Left nephrectomy (adenocarcinoma) & \\
\hline & Stomach resection (cancer) & \\
\hline & Right hemicolectomy (ischaemia of the right colon) & Incisional hernia after right hemicolectomy \\
\hline & Cholecystectomy and hernia repair & Recurrence \\
\hline & Open hernia repair with synthetic mesh & Recurrence \\
\hline \multirow[t]{2}{*}{11} & Appendectomy & Wound infection, incisional hernia \\
\hline & Open hernia repair & Recurrence \\
\hline \multirow[t]{2}{*}{12} & Laparoscopy, conversion, appendectomy & Wound infection, incisional hernia \\
\hline & Open hernia repair & Recurrence \\
\hline \multirow[t]{2}{*}{13} & Appendectomy & Wound infection, incisional hernia \\
\hline & Open hernia repair with synthetic mesh & Recurrence \\
\hline
\end{tabular}


Table II. Cont.

\begin{tabular}{|c|c|c|}
\hline No. & Previous operations & Postoperative complications \\
\hline \multirow[t]{4}{*}{14} & Appendectomy in the past & \\
\hline & Hysterectomy 1979 & \\
\hline & Cholecystectomy 1998 & \\
\hline & Peptic ulcer perforation 2001 & Huge ventral hernia \\
\hline \multirow[t]{4}{*}{15} & Appendectomy & Incisional hernia \\
\hline & Open hernia repair & Recurrence \\
\hline & IPOM & Bleeding, haemorrhagic shock \\
\hline & Relaparotomy, removal of mesh & Ventral hernia \\
\hline
\end{tabular}

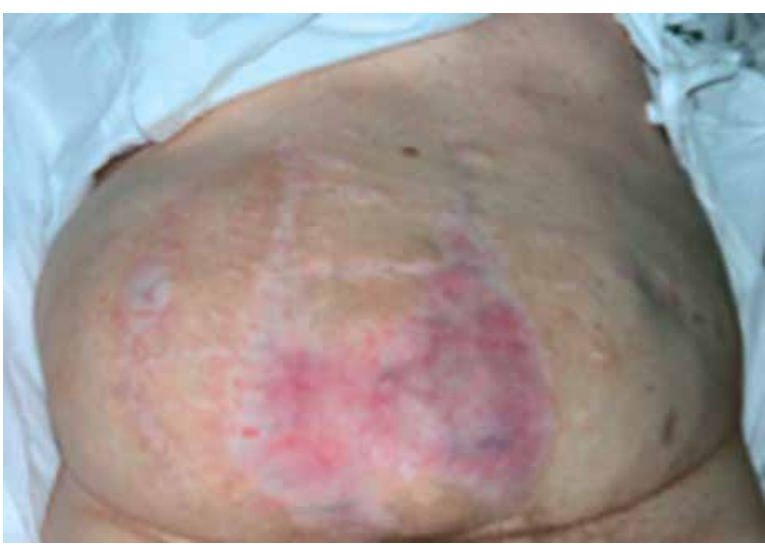

Photo 1. Recurrent hernia after laparotomy and the primary suture repair complicated by wound infection

repairs of hernias. In this group there was 1 patient with a body mass index above $31 \mathrm{~kg} / \mathrm{m}^{2}$, referred to our department from the emergency unit with symptoms suggesting intestinal occlusion. Three patients had recurrent hernia after appendectomy complicated by wound infection and open repair of the hernia afterwards. One patient had a huge hernia after numerous laparotomies (cholecystectomy, hysterectomy, appendectomy, peptic ulcer perforation), and 1 patient after open repair of hernia after appendectomy, laparoscopic intraperitoneal onlay mesh (IPOM) repair of recurrent hernia complicated by haemorrhagic shock requiring removal of the mesh during urgent relaparotomy afterwards.

In 14 cases the combined procedure was performed by using synthetic materials covered from one side (the abdominal cavity) by a substance which creates a thin layer to keep the mesh from adhering to intra-abdominal organs. We used four types of these materials: Ventralight, Parietex,

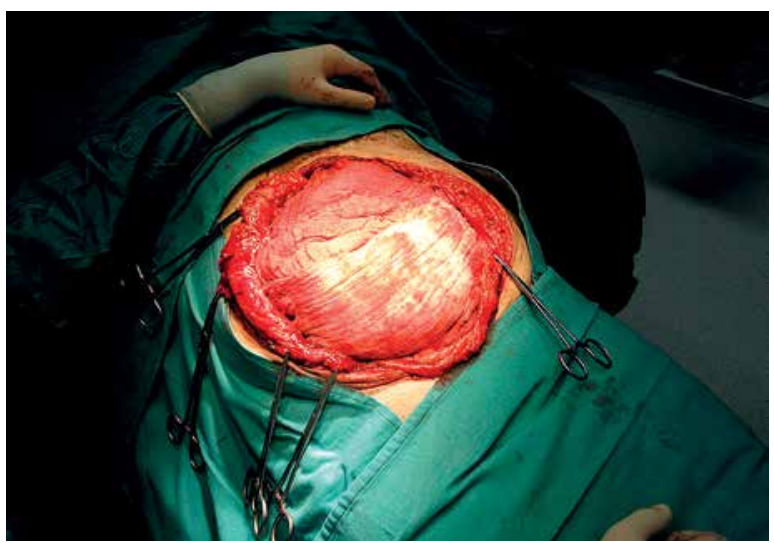

Photo 2. Open part of the operation. Perioperative view after removing large scar

DualMesh and C-qur. In 1 case a biological implant (Periguard) was used. Sizes of meshes depended on the size of hernias and were approximately $15 \mathrm{~cm} \times$ $20 \mathrm{~cm}$ or $20 \mathrm{~cm} \times 30 \mathrm{~cm}$.

\section{Operating technique}

The open part of the operation (laparotomy) ensured extensive and safe adhesiolysis, reduction of the hernia content into the peritoneal cavity, proper placement of the laparoscopic tools and mesh into the peritoneal cavity (Photo 2), minimization of the risk of intestinal perforation, and the closure of the abdominal wall, sometimes using sutures which prevent dehiscence. The next step was the laparoscopic part of the procedure, intraperitoneal placement of the mesh after the reduction of the intraperitoneal pressure to 7-8 $\mathrm{mm} \mathrm{Hg}$. The mesh should have appropriate size, covering the actual hernia size edges for at least $5-7 \mathrm{~cm}$, and then it is laparoscopically fixed with transfascial stay stitches (Protac or Absor- 


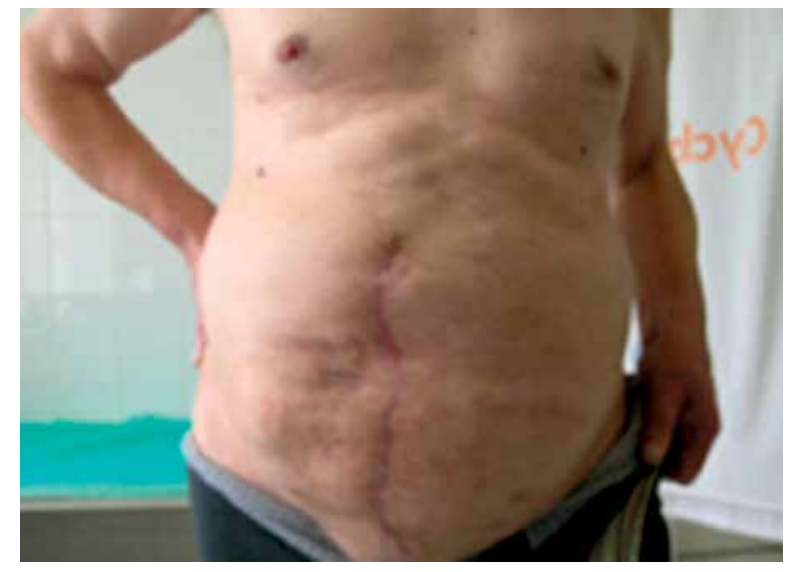

Photo 3. Postoperative appearance 6 months after the hybrid repair

batack). The total operative time ranged from 100 to $180 \mathrm{~min}$.

\section{Results}

The best therapeutic and cosmetic result can be achieved by using the combined laparoscopic and open technique. Within a maximum follow-up period of 32 months, in spite of standard antibiotic prophylaxis (one dose of ceftriaxone 30 min before the operation) used in our department, two deep wound infections were observed. In a 65-year-old patient with diabetes and ischaemic heart disease, infection occurred 2 months after hybrid repair with a biological implant (Periguard). Another patient was 78 with diabetes, ischaemic heart disease, renal failure, after cancer surgery (stomach resection) and right hemicolectomy; infection occurred 4 months after hybrid repair with synthetic mesh (Parietex). Both patients were operated on and infected meshes were removed.

In the other cases the postoperative course was uneventful. Moreover, postoperative pain has remained within 2-4 on the Visual Analogue Scale. Within our follow-up period, there were no signs of recurrence of hernia or worsening quality of life.

\section{Discussion}

The technological progress achieved in the area of polymerization and production of new synthetic meshes contributes to the improvement of the surgical technique for incisional hernia repair. Open mesh repairs have a recurrence rate of $10 \%$ to $20 \%$, but the number of serious complications appear- ing in the postoperative course (e.g. pain, infection, seroma formation) is rather high. In 1993, LeBlanc and Booth were the first to use a special synthetic mesh in the laparoscopic procedure [12]. It was a big step in the treatment of ventral hernia, and from that time the miniinvasive mesh repair has rapidly become accepted among general surgeons for multiple reasons. It has a remarkably low recurrence rate across many series. Moreover, many authors have highlighted the lower incidence of perioperative complications and shorter hospital stay [13-16]. Another value of the laparoscopic procedure is the improved visualization offered by modern optical tools to reduce the incidence of missed hernias and easy fixation of a large mesh to the abdominal wall. The benefits of laparoscopy in obese patients with regards to exposure and decreased wound complications make this technique ideal. However, there are still some problems connected with complicated, large incisional hernias, including the frequency of seromas, unchanged scar appearance, and massive adhesions after previous operations (especially dangerous during placement of laparoscopic tools into the abdominal cavity). We are convinced that these problems could be solved by combining the two surgical techniques. The open technique ensures safe adhesiolysis, minimizing perforation of abdominal organs, the ability to place a large mesh into the abdominal cavity, and better cosmetic appearance of a single midline incision (Photo 3). According to initial reports of some authors, by using the combined technique, the ultimate results would be the minimal recurrence and hospital stay similar to laparoscopic mesh repair [17-20]. Nowadays, in our department the combined technique is the method of choice for the repair of complicated, recurrent incisional hernias. Unfortunately, the very high costs of the operation and synthetic materials needed limit the opportunities to perform this method.

Despite considerable improvements in incisional hernia treatment, contaminations or infections associated with incisional hernias remain a challenge for many surgeons. The use of innovative materials, such as biological implants, is thought to be a suitable choice in such situations. Recently, the list of biologic available materials is getting longer. They differ based on their source (human or animal), composition (dermal, pericardial or submucosa) and methods of processing (stripping, cross-linking). Biological grafts are acellular collagen matrices implant- 


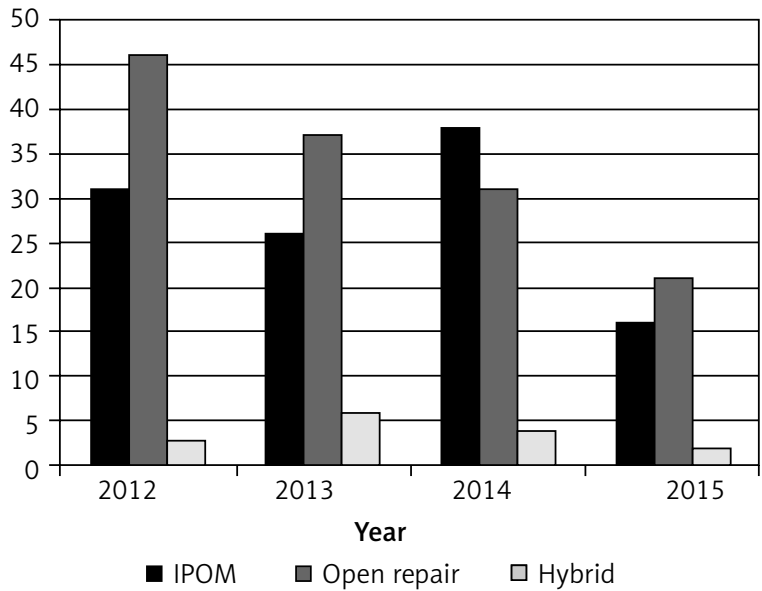

Figure 1. Distribution of open, IPOM and hybrid techniques in our department

ed during hernia repair to facilitate native tissue incorporation. Some authors report use of biological implants in hernia repair in a potentially contaminated or infected surgical field [9, 21-23]. In our research one deep infection was observed after hybrid implantation of bovine pericardium cross-linked with glutaraldehyde (Periguard) in a patient with higher risk of infection. Systemic antibiotic therapy was not used as routine in this case because we were convinced that it was not necessary.

\section{Conclusions}

The authors are convinced that it is impossible to compare the results presented in the article to a group of patients treated using other methods. Patients operated on using the hybrid technique comprise a small, specially selected group, often with many comorbidities, after numerous complicated operations including open or laparoscopic hernia repair. The distribution of open, IPOM and hybrid techniques in our department between 2012 and 2015 is presented in Figure 1. Moreover, anatomical location of the defects, the type of mesh and the fixation methods used in the hybrid technique may differ from the ones used in open or laparoscopic IPOM.

In our view, the combined technique presented in this report proved to be an optimal and safe solution in cases of recurrent, complicated, large incisional or ventral hernias. A longer follow-up period is required to evaluate the effectiveness of the method. We are also convinced that more evidence is needed in order to determine situations where expensive meshes might be justified.

\section{Conflict of interest}

The authors declare no conflict of interest.

\section{References}

1. Mackiewicz Z. The modern treatment of ventral hernias. PZWL, Warsaw 2006; 152-9.

2. Jankins E, Yom V, Melman L, et al. Clinical predictors of operative complexity in laparoscopic ventral hernia repair: a prospective study. Surg Endosc 2010; 24: 1872-7.

3. Lee $Y$, Iqubal A, Vitamvas $M$, et al. Is it safe to perform laparoscopic ventral hernia repair with mesh in elderly patients? Hernia 2008; 12: 239-42.

4. Romańczuk M, Mitura K, Wróblewski T. A comparison of methods and results of ventral incisional hernia repair. Videosurgery Miniinv 2006; 1: 95-100.

5. Wysocki A, Budzyński P. Implants in surgery of hernias. Med Prakt 2010; 1: 9-15.

6. Janczak D, Litarski A, Merenda M. Use of synthetic mesh in abdominal wall hernias repair. Polimery w Medycynie 2011; 41: 13-8.

7. Carlson MA, Frantzides CT, Shostrom VK, et al. Minimally invasive ventral herniorrhaphy: an analysis of 6,266 published cases. Hernia 2008; 12: 9-22.

8. Sajid MS, Bokhari SA, Mallick AS, et al. Laparoscopic versus open repair of incisional/ventral hernia: a meta-analysis. Am J Surg 2009; 197: 64-72.

9. Mariette C, Briez N, Denies F, et al. Use of biological mesh versus standard wound care in infected incisional ventral hernias, the SIMBIOSE study: a study protocol for a randomized multicenter controlled trial. Trials 2013; 14: 131 (http://www.trialsjournal.com/content/14/1/131).

10. Campanelli G, Catena F, Ansaloni L. Prosthetic abdominal wall hernia repair in emergency surgery: from polypropylene to biological meshes. World J Emerg Surg 2008; 3: 33.

11. El-Hayek KM, Chand B. Biologic prosthetic materials for hernia repairs. J Long Term Eff Med Implants 2010; 20: 159-69.

12. LeBlanc K, Booth WF. Laparoscopic repair of incisional abdominal hernias using expanded polytetrafluoroethylene: preliminary findings. Surg Laparoscopic Endosc 1993; 3: 39-41.

13. McKinlay RD, Park A. Laparoscopic ventral incisional hernia repair: a more effective alternative to conventional repair of recurrent incisional hernia. J Gastrointest Surg 2004; 8: 670-4.

14. Bencini L, Sanchez LJ, Bofii B, et al. Incisional hernia repair retrospective comparison of laparoscopic and open techniques. Surg Endosc 2003; 17: 1546-51.

15. Śmietański M, Bigda J, Iwan K, et al. Assessment of usefulness of different tacks in laparoscopic ventral hernia repair (IPOM). Surg Endosc 2007; 21: 925-8.

16. Trojanowski P, Kwiatkowski A, Paśnik K. et al. Modern methods of treatment of incisional hernias. Pol Merk Lek 2009; 26: 569-71.

17. Griniatsos J, Yiannakopoulou E, Tsechpenakis A, et al. A hybrid technique for recurrent incisional hernia repair. Surg Laparosc Endosc Percutan Tech 2009; 19: 177-80.

18. Ji Y, Zhan X, Wang Y, et al. Combined laparoscopic and open technique for the repair of large complicated incisional hernias. Surg Endosc 2013; 27: 1778-83. 
19. Neff M, Cantor B, Geins WP. Laparoscopic-assisted primary repair of a complicated ventral incisional hernia. JSLS 2005; 9: 241-4.

20. Staikes N, Quasebarth M, Brunt LM. Hybrid ventral hernia repair: techniques and results. Hernia 2013; 17: 627-32.

21. Alaedeen DI, Lipman J. The single-staged approach to the surgical management of abdominal wall hernias in contaminated fields. Hernia 2006; 11: 41-5.

22. Bilsel Y, Abci I. The search for ideal hernia repair: mesh materials and types. Int I Surg 2012; 10: 317-21.

23. Montgomery A. The battle between biological and synthetic meshes in ventral hernia repair. Hernia 2013; 17: 3-11.

Received: 7.06.2015, accepted: 20.10.2015. 